\title{
Development of Graphical User Interfaces to Visualize Meteorological Data
}

by

R. L. Buckley

Westinghouse Savannah River Company

Savannah River Site

Aiken, South Carolina 29808

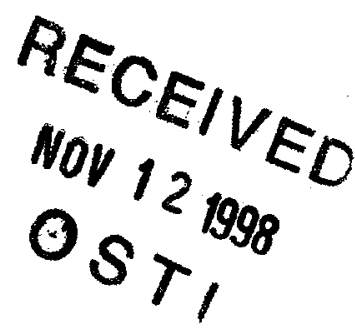

A document prepared for 15TH INTERNATIONAL CONFERENCE ON INTERACTIVE INFORMATION AND PROCESSING SYSTEMS FOR METEOROLOGY, OCEANOGRAPHY, AND HYDROLOGY at Dallas, TX, USA from $1 / 10 / 99-1 / 15 / 99$.

\section{DOE Contract No. DE-AC09-96SR18500}

This paper was prepared in connection with work done under the above contract number with the U.S. Department of Energy. By acceptance of this paper, the publisher and/or recipient acknowledges the U. S. Government's right to retain a nonexclusive, royalty-free license in and to any copyright covering this paper, along with the right to reproduce and to authorize others to reproduce all or part of the copyrighted paper. 


\section{DISCLAIMER}

This report was prepared as an account of work sponsored by an agency of the United States Government. Neither the United States Government nor any agency thereof, nor any of their employees, makes any warranty, express or implied, or assumes any legal liability or responsibility for the accuracy, completeness, or usefulness of any information, apparatus, product, or process disclosed, or represents that its use would not infringe privately owned rights. Reference herein to any specific commercial product, process, or service by trade name, trademark, manufacturer, or otherwise does not necessarily constitute or imply its endorsement, recommendation, or favoring by the United States Government or any agency thereof. The views and opinions of authors expressed herein do not necessarily state or reflect those of the United States Government or any agency thereof.

This report has been reproduced directly from the best available copy.

Available to DOE and DOE contractors from the Office of Scientific and Technical Information, P. O. Box 62, Oak Ridge, TN 37831; prices available from (423) 576-8401.

Available to the public from the National Technical Information Service, U. S. Department of Commerce, 5285. Port Royal Road, Springfield, VA 22161. 


\section{DISCLAIMER}

Portions of this document may be illegible in electronic image products. Images are produced from the best available original document. 


\author{
Robert L. Buckley* \\ Savannah River Technology Center, Westinghouse Savannah River Company \\ Aiken, South Carolina 29808
}

\section{INTRODUCTION}

The availability of meteorological data in various forms has increased in recent years due to improved communication and expanded computational storage. At the Savannah River Technology Center (SRTC) of the Savannah River Site (SRS), a considerable amount of data from Weather Services International (WSI) is collected and archived on a daily basis. Both surface and upper-air observations are collected by governmental agencies around the world at varying time intervals $(1,3$, or 12 hours) and placed into a format specified by the World Meteorological Organization (WMO). The upper-air (sounding) data are collected at 12-hr increments from stationary and mobile (ship) locations while the surface data are collected as synoptic bulletins (every 3 hours) and in METAR (hourly) format (WMO-No. 306, 1995). It is important to be able to present the information contained in these data to an interested customer in a quick, efficient manner. This report focuses on the graphical display of the surface observations and upper-air data from stationary locations.

Devices for depicting this information have been developed using the Interactive Data Language (IDL, version 4.0.1, IDL User's Guide, 1995). The user is prompted for the time and general location of interest. For the surface observations, a map is drawn on which relevant surface observations are plotted. The user may examine individual stations in more detail. For the upper-air reports, possible sounding locations are mapped and the user is given the option of examining one or more stations in the region. Thermodynamic diagrams for the selected station are generated. The procedure that the user follows is dictated in each case by a graphical user interface (GUI). The purpose of this report is to briefly describe the importance of both upper-air and surface plots, the design of the interfaces, and possible applications.

\section{BACKGROUND}

Surface observations from around the world may be plotted onto maps in a compact form that contain much information. An internationally developed symbolic station model has been adopted, where a station circle is used to represent the location of each station. Data pertaining to various meteorological attributes (i.e. temperature, pressure) are arranged around the circle in a fixed manner, while a barb extending outward from the circle illustrates wind speed and direction. Total sky coverage is denoted by the degree to which the circle is filled. (Overcast conditions imply a totally filled circle, while clear skies warrant an unfilled, hollow circle). By plotting a number of symbolic station models on a map and over a period of time, meteorologists can define the development and movement of weather systems (Lutgens and Tarbuck, 1989).

Corresponding author address: R. L. Buckley, Savannah River Technology Center, Building 773-A, Aiken SC 29808. Copyright 1998, Westinghouse Savannah River Company.
A particularly effective way of illustrating weather conditions at a given upper-air location is through the use of thermodynamic diagrams relating pressure, temperature and moisture. Meteorologists frequently use a 'skew- $T$ log- $p$ ' diagram containing a logarithmic pressure $(p)$ scale along the ordinate and temperature (T) skewed at an angle to the right along the abscissa. This form is useful in providing atmospheric analyses over a large range of pressures (up to $100 \mathrm{mb}$ ) on a single chart.

The need for such diagrams is to convey information regarding upper-air temperatures and lapse rates (a change in air temperature with height (pressure), assuming a hydrostatic atmosphere). If a small mass of dry air (parcel) changes temperature solely with height (and not due to processes such as conduction, radiation, or convective mixing), the process is said to be adiabatic. For an adiabatic process, the temperature of an air parcel will cool as it rises and warm as it descends. Therefore, a dry adiabatic line (or dry adiabat) describes the temperature variation of a dry air parcel with height. Equal areas on a skew- $T$ log- $p$ thermodynamic diagram represent equal energy. This makes the diagrams powerful tools in analyzing atmospheric convection.

If water vapor exists in a rising air parcel, a level is eventually reached where sufficient cooling occurs to cause saturation of the parcel. The temperature at which this saturation occurs is the dew point. Above this level, condensation of surplus moisture occurs. The latent heat associated with this phase change reduces the adiabatic cooling rate of dry ascending air. Saturated adiabats are thus used to indicate the temperature variation of the saturated air parcel with height (Bluestein, 1992). The dry and saturated adiabats are commonly plotted on the skew- $T$ log-p diagram. In addition, lines of constant saturation mixing ratio (the ratio of water vapor mass to a unit mass of dry air $\left.\left(\mathrm{g} \mathrm{kg}^{-1}\right)\right)$ are illustrated in the diagrams.

The upper-air data typically consist of dry-bulb temperature and dew point temperature as a function of pressure (height). By superimposing dry-bulb and dew point temperature values on the skew- $T$ log-p diagram containing both dry and saturated adiabats, information regarding atmospheric stability and convective formation can be discerned (Bluestein 1992). Also, wind barbs indicating the wind speed and direction of horizontal flow for a given pressure level may be plotted on the diagram, yielding further atmospheric information to the user.

\section{INTERFACE DESIGN}

The use of a menu-driven GUI allows the user to more easily input and display upper-air soundings or surface observations than a code requiring specific keyboard inputs. A series of procedures has been written in IDL to produce each GUI. The synoptic bulletin surface observations (or FM-12-X, WMO-No. $306,1995)$ are available from WSI every 3 hours beginning at 00 Greenwich Mean Time (GMT, often reported as $Z$ (Zulu) time), while METAR data (aviation routine weather reports, FM-15-X) are available on an hourly basis. For upper-air reports $(F M-35-X)$, data is 


$$
\text { WSRC-TR }-98-80166^{\circ}
$$

archived from WSI at 00 and 12Z. Data from all reporting stations worldwide for a particular data-type are contained within a given file (named with respect to the time at which the observation is valid).

For both the surface and the upper-air GUI, the user is first prompted to select a time and central location from which to examine data. Meteorological information is gathered in a user-specified region about this central location, entered as a latitude and longitude. The absolute value of the center latitude must be $\leq 90^{\circ}$, defined positive to the north. Likewise, the absolute center longitude must be $\leq 180^{\circ}$, defined positive to the east.

A user-selected sampling range $(\mathrm{km})$ is used to determine maximum and minimum latitudes and longitudes from which to sample possible station data (limited to $<10000 \mathrm{~km}$ ). The range refers to the total distance along constant latitude (west-to-east) and longitude (north-to-south) lines traversing the center location. Thus, for a $100-\mathrm{km}$ range, stations up to 50 $\mathrm{km}$ east and $50 \mathrm{~km}$ west would be included. Note that the domain of interest is not allowed to extend over either of the poles, but is instead assumed to stop at the pole. Note also that large domains (i.e. $>5000 \mathrm{~km}$ ) often generate maps with many stations which tend to become cluttered (especially for the more dense surface network), thus reducing its effectiveness in imparting information to the user.

\subsection{Surface Observations}

Once a location and time have been chosen for the surface observations, a map is drawn and surface observations in symbolic station format are superimposed and centered at the station's geographic location. A datafile containing the latitude, longitude, and elevation above sea level associated with a unique 5-digit integer station identification (station ID) is accessed for the synoptic bulletins, while a unique 4digit character station ID and datafile exists for the METAR dataset. The data for the synoptic bulletins are stored in 5-character sequences and are decoded into a series of arrays. Similar decoding procedures have been developed for the METAR data records.

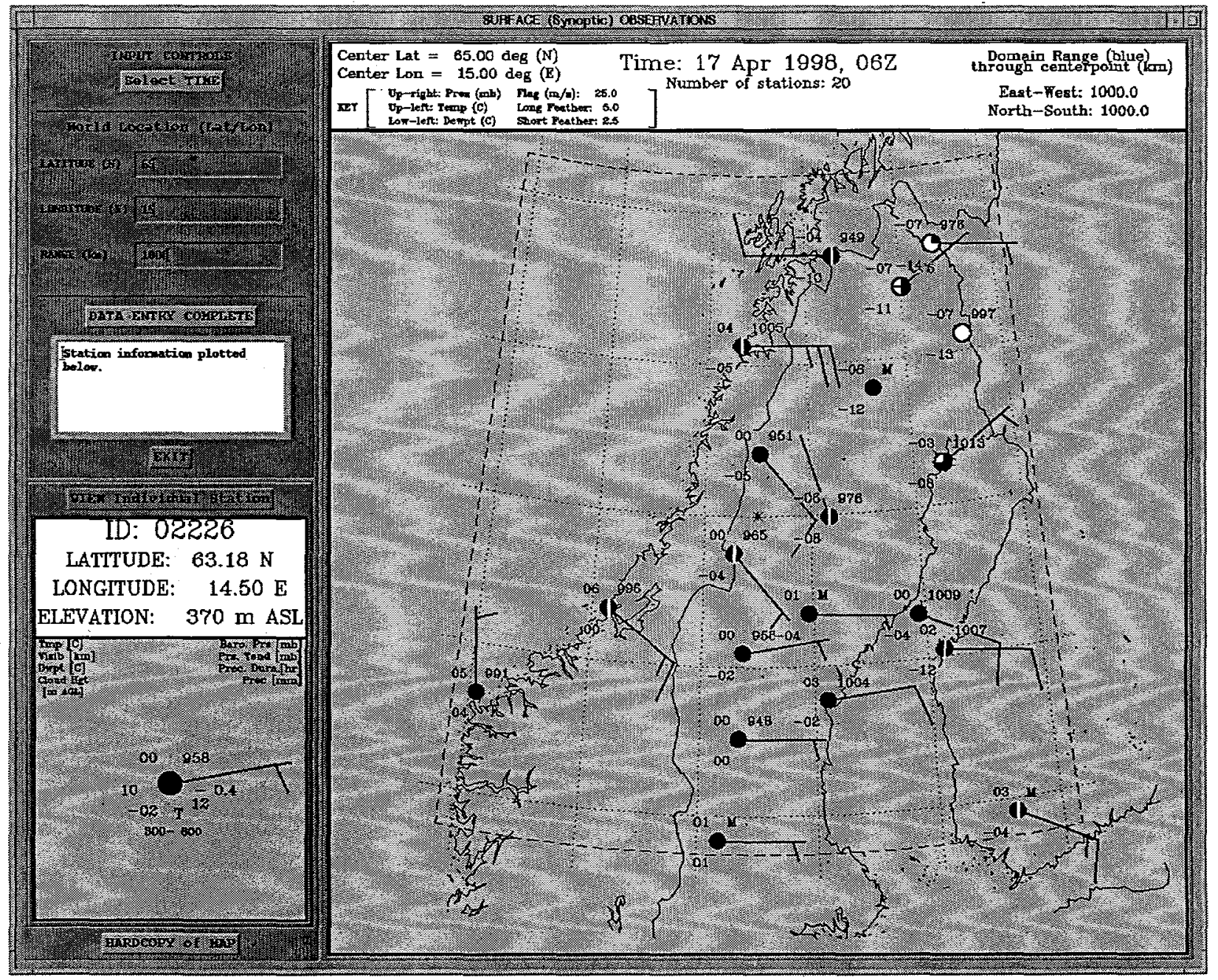

Figure 1: Graphical user interface layout for displaying surface observations. This map shows the Scandinavian region at 06Z, 17 April 1998, as well as detailed conditions for Ostersund, Sweden (ID=02226). 


\section{WSRC - TR - $98-001.66$}

Values shown for each station include the temperature $\left({ }^{\circ} \mathrm{C}\right)$, dew point temperature $\left({ }^{\circ} \mathrm{C}\right)$, barometric pressure (mb), sky coverage, and wind speed and direction as a barb. Other information displayed on the surface GUI map includes the domain range, center location, the time at which observations are valid, the number of stations contained within the domain, and a legend explaining the meaning of the various parts of each station report.

If more detailed information for an individual station is desired, the user may select the station from the map using the mouse. A separate image is created showing the station identification (ID), geographical location, elevation above sea level (m), and meteorological information as before. Also shown (if available from the data record) is the visibility $(\mathrm{km})$, low level cloud height base $(m)$, pressure tendency over the past 3 hours $(\mathrm{mb})$, precipitation $(\mathrm{mm})$, and the duration over which the precipitation has been received (hr).

Figure 1 is an illustration of the surface GUI (for a synoptic bulletin) and its components. (Note that much information is lost without color). The time and location are input in the upper left portion. When the program is executed, this is the only part of the GUI that is visible to the user. After successful data entry, a map is produced to the right, with depictions of station locations and other pertinent information. This particular plot is centered on Sweden $\left(65^{\circ} \mathrm{N}, 15^{\circ} \mathrm{E}\right)$ on 17 April 1998 and contains 20 stations. An area containing comments and instructions to the user is shown on the middle-left side of the GUI. For this example, winds are generally from the east, with temperatures ranging from -8 to $+6^{\circ} \mathrm{C}$, with cooler temperatures to the north. Dew point temperatures reveal dryer conditions to the north and moist conditions (i.e. relative humidities $\sim 100 \%$ ) in the southern-most portion of the domain in Sweden. Most of the region appears to be overcast, with the exception of the northeastern corner. As indicated in the lower-left corner, an option exists within the GUI to obtain a hardcopy of this map.

An individual station has been selected as well and is shown in the lower left portion of the GUI. For this particular time (06Z, 17 April 1998) and location (Ostersund, Sweden), winds are from the eastnortheast between 2.5 and $5.0 \mathrm{~m} \mathrm{~s}^{-1}$. The barometric pressure is $958 \mathrm{mb}$ and has dropped $0.4 \mathrm{mb}$ over the previous 3 hours, while a trace of precipitation has fallen over the past 12 hours. While sky coverage indicates totally overcast conditions, the lowest cloud base is estimated to be 300 to $600-\mathrm{m}$ above ground level. The temperature is $0^{\circ} \mathrm{C}$ and the dew point temperature is $-2^{\circ} \mathrm{C}$, while the visibility is $10 \mathrm{~km}$.

\subsection{Upper-Air Observations}

After the time and location of upper-air examination is satisfactorily entered, a map is drawn showing the countries (continents) in which soundings are desired. A unique 5-digit integer station ID exists for each record (as in the surface synoptic bulletins) from which location and elevation are determined. Each station ID within the selected area is also shown on the map. If stations exist within the domain of interest, data associated with the appropriate station ID are collected from the datafile for the given time. With the selection of a particular station by the user, the thermodynamic diagram is then created with temperature and dew point $\left({ }^{\circ} \mathrm{C}\right)$ superimposed on the diagram.

Parts $A$ and $B$ of the FM-35-X dataset are utilized. Part A consists of geopotential height $(m)$, temperature $\left({ }^{\circ} \mathrm{C}\right)$, dew point depression $\left({ }^{\circ} \mathrm{C}\right)$, wind direction (deg), and wind speed (knots or $\mathrm{m} \mathrm{s}^{-1}$ ) at mandatory pressure levels (mb). As in the synoptic surface bulletins, these data are stored in 5-character sequences and are decoded into a series of arrays. Similarly, Part B consists of temperature $\left({ }^{\circ} \mathrm{C}\right)$ and dew point depression $\left({ }^{\circ} \mathrm{C}\right)$ at significant pressure levels $(\mathrm{mb})$. These data are also decoded and combined with the mandatory pressure level information to produce the thermodynamic skew- $T$ log-p diagram. If wind data are available (Part $A$ ), wind barbs are also plotted on the sounding. Magnification of the sounding for a selected area within the image is available, as well as an option for hardcopy output. At this point, the user may select other stations to view for the given time, or select a new time and/or place from which to examine sounding data.

An illustration of the GUI and its components is shown in Fig. 2. As in the surface GUI, the time and location is input in the upper left portion. After successful data entry, a map is produced in the top center, depicting station locations and other pertinent information. This particular plot is centered on southern Europe near Italy and contains 6 stations. Those stations that contain data for the selected time $(00 \mathrm{Z}, 17$ February 1998) are indicated in the upper right portion of the figure. An area containing comments and instructions to the user is shown in both the upper left and upper right areas of the GUI.

The thermodynamic diagram for Lyon, France is shown in the bottom half of the figure, with dew point temperature and dry-bulb temperature shown as solid white lines. Saturated adiabats $\left({ }^{\circ} \mathrm{C}\right)$ are the solid dark lines which curve from right to left with decreasing pressure (and labeled at $700 \mathrm{mb}$ ). The temperature for this sounding closely follows a saturated adiabat between 10 and $15^{\circ} \mathrm{C}$. Also shown (though difficult to discern) are dry adiabats $\left({ }^{\circ} \mathrm{C}\right)$ which are solid lines labeled at a skewed angle in the left portion of the diagram and saturation mixing ratio $\left(\mathrm{g} \mathrm{kg}^{-1}\right)$ lines which are dashed and nearly vertical (labeled at 200 and 1000 $\mathrm{mb}$ ). This sounding illustrates a temperature increase (i.e. inversion) between 850 and $800 \mathrm{mb}$ and a dryer atmosphere between 800 and $400 \mathrm{mb}$. Wind barbs are shown at the right edge, and indicate northnorthwesterly winds near the surface, which shift to westerly and increase in intensity above $700 \mathrm{mb}$. (A legend defining barb feathers and flags is given in the lower right corner).

\section{CONCLUSIONS}

The visual information depicted in these surface and upper-air plots, are useful in the determination of frontal location and atmospheric convective activity and are often used by meteorologists. However, such data are usually not archived and plots from readily available sources such as WSI are only valid at the current time. If results are archived, they are usually in the form of plots for a specified station or geographic region. The graphical user interfaces as written here are unique in that they access data at any time and global location.

Perhaps of more importance is the application of this meteorological data in other models. Once a dataset is decoded, it can be used as input to numerical mesoscale models. Realistic surface fields can be generated using standard interpolation routines, or in combination with upper-air soundings and/or largescale pressure fields to initialize wind, temperature, and moisture fields in multiple-dimensions. Results from the numerical models may also be validated by comparison with the observed data. 


\section{WSRC-TR-98-00166}

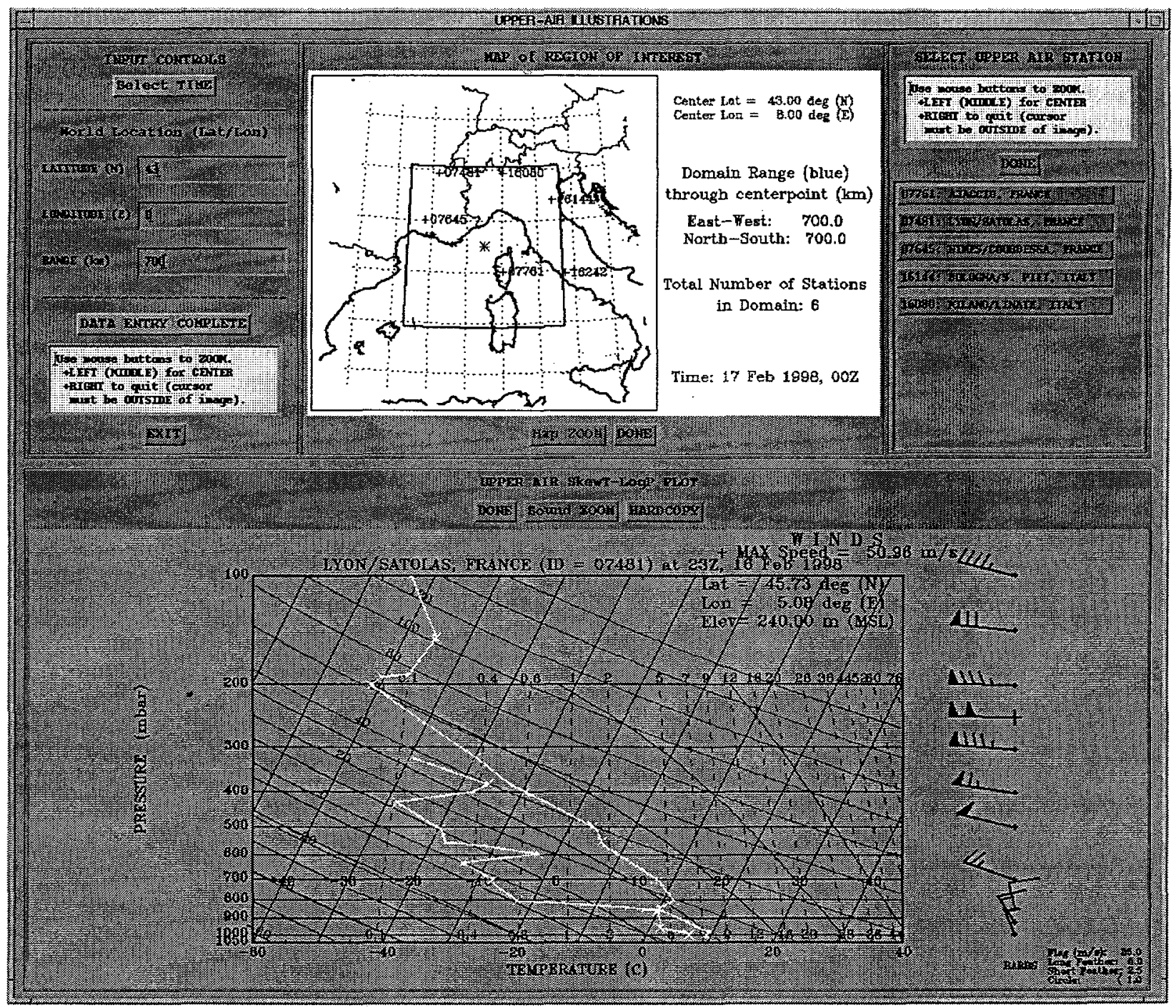

Figure 2: Graphical user interface layout for the upper-air observations. This example shows a map of south-central Europe with a sounding for Lyon, France $(I D=07481$ ) on $23 Z, 16$ February 1998).

Another obvious application of the data is in the direct input of wind fields for dispersion modeling. Dispersion models have applications in air-quality and environmental assessments, emergency response, and non-proliferation. Often, these models require only twodimensional winds as input to reduce computational time, and the existence of readily available surface observations necessarily leads to more accurate plume predictions. This could be particularly advantageous in emergency response applications, since observations are typically available several hours before numerical model guidance.

\section{REFERENCES}

Bluestein H. B., 1992: Synoptic-Dynamic Meteorology in Midlatitudes, Volume 1: Principles of Kinematics and Dynamics, Oxford Press University, Inc., 431 pp.
IDL User's Guide, Interactive Data Language, Version 4, March 1995: Research System Inc., Boulder CO, pp. 21.1-21.34.

Manual on Codes, International Codes, Volume I.1. Part A-Alphanumeric Codes, WMO-No. 306, 1995: World Meteorological Organization, Secretariat of the World Meteorological Organization, Geneva, Switzerland.

Lutgens F. K., and E. J. Tarbuck, 1989: The Atmosphere: An introduction to Meteorology, Fourth Edition. Prentice Hall, Englewood Cliffs, NJ (USA), pp. 439-444. 